\title{
Effect of Flibanserin Treatment on Body Weight in Premenopausal and Postmenopausal Women with Hypoactive Sexual Desire Disorder: A Post Hoc Analysis
}

\author{
Susan G. Kornstein, MD, James A. Simon, MD,2 Stuart C. Apfel, MD, \\ James Yuan, MD, PhD, MBA, Krista A. Barbour, PhD, MPH, and Robert Kissling, $\mathrm{MD}^{4}$
}

\begin{abstract}
Background: Flibanserin, a 5- $\mathrm{HT}_{1 \mathrm{~A}}$ agonist and 5- $\mathrm{HT}_{2 \mathrm{~A}}$ antagonist, is indicated for the treatment of acquired, generalized hypoactive sexual desire disorder (HSDD) in premenopausal women. This post hoc analysis evaluated the effect of flibanserin treatment on body weight in premenopausal and postmenopausal women with HSDD.

Materials and Methods: This analysis included three 24-week, double-blind, placebo-controlled studies of flibanserin $100 \mathrm{mg}$ each bedtime (qhs) in premenopausal women, a similarly designed study in postmenopausal women, and a 52-week, open-label extension study in premenopausal women.

Results: In a pooled analysis of premenopausal women, mean baseline body mass index (BMI) was $27.0 \mathrm{~kg} / \mathrm{m}^{2}$ in the flibanserin group $(n=1227)$ and $26.8 \mathrm{~kg} / \mathrm{m}^{2}$ in the placebo group $(n=1238)$. Among patients who completed 24 weeks of treatment, least squares (LS) mean weight change was $-1.4 \mathrm{~kg}$ in the flibanserin group $(n=1010)$ and $-0.1 \mathrm{~kg}$ in the placebo group $(n=1066 ; p<0.0001)$. Weight loss $\geq 5 \%$ from baseline was reported in $21.0 \%$ of patients who received flibanserin and $7.8 \%$ of patients who received placebo; weight loss $\geq 10 \%$ was reported in $3.8 \%$ and $2.0 \%$ of patients, respectively. In postmenopausal women, mean baseline BMI was $27.7 \mathrm{~kg} / \mathrm{m}^{2}$ in the flibanserin group $(n=467)$ and $27.3 \mathrm{~kg} / \mathrm{m}^{2}$ in the placebo group $(n=480)$. LS mean weight change at week 24 was $-1.8 \mathrm{~kg}$ in the flibanserin group $(n=385)$ and $-0.1 \mathrm{~kg}$ in the placebo group $(n=425 ; p<0.0001)$, with weight loss $\geq 5 \%$ reported in $24.7 \%$ and $7.3 \%$ of patients, respectively, and weight loss $\geq 10 \%$ reported in $5.2 \%$ and $1.7 \%$, respectively. In HSDD patients with $>12$ months $(n=880)$ and $>18$ months $(n=637)$ of exposure to flibanserin, mean weight change was -1.0 and $-1.2 \mathrm{~kg}$, respectively; $25.4 \%$ and $26.9 \%$ of patients, respectively, experienced weight loss $\geq 5 \%$ from baseline, and $7.8 \%$ and $8.4 \%$, respectively, experienced weight loss $\geq 10 \%$.
\end{abstract}

Conclusions: Women treated with flibanserin for HSDD may experience weight loss.

Keywords: body weight, flibanserin, reproductive health, sexuality, weight loss

\section{Introduction}

$\mathbf{F}$ LIBANSERIN IS INDICATED for the treatment of acquired, generalized hypoactive sexual desire disorder (HSDD; not limited to certain types of stimulation, situation, or partner and developed after a period of normal sexual functioning) in premenopausal women and is the only U.S. Food and Drug Administration (FDA)-approved treatment for HSDD. ${ }^{1,2}$ Flibanserin is a postsynaptic $5-\mathrm{HT}_{1 \mathrm{~A}}$ agonist and $5-\mathrm{HT}_{2 \mathrm{~A}}$ antagonist that has been shown to induce decreases in serotonin and increases in dopamine and norepinephrine in certain regions of the cerebral cortex. ${ }^{3-6}$

\footnotetext{
${ }^{1}$ Department of Psychiatry and Institute for Women's Health, Virginia Commonwealth University, Richmond, Virginia.

${ }^{2}$ Department of Obstetrics and Gynecology, George Washington University School of Medicine, Washington, District of Columbia.

${ }^{3}$ The Saul R. Korey Department of Neurology, Albert Einstein College of Medicine, Yeshiva University, New York, New York.

${ }^{4}$ Valeant Pharmaceuticals North America, LLC, Bridgewater, New Jersey.
}

(c) Susan G. Kornstein, et al. 2017; Published by Mary Ann Liebert, Inc. This article is available under the Creative Commons License CC-BY-NC (http://creativecommons.org/licenses/by-nc/4.0). This license permits non-commercial use, distribution and reproduction in any medium, provided the original work is properly cited. Permission only needs to be obtained for commercial use and can be done via RightsLink. 
By modulating these neurotransmitters, flibanserin is hypothesized to restore balance to the activity of excitatory and inhibitory influences on the regulation of a healthy sexual response. ${ }^{7,8}$ The efficacy and safety of flibanserin in the treatment of HSDD have been demonstrated in randomized clinical trials of premenopausal and postmenopausal women $^{9-13}$; however, flibanserin is not approved by the FDA for use in postmenopausal women.

Serotonin neurons play a complex role in the regulation of weight and metabolism, and pharmacologic agents with serotonin-related activity have been shown to increase or decrease body weight. ${ }^{14-19}$ Some serotonergic medications (e.g., certain selective serotonin reuptake inhibitors [SSRIs]) are associated with weight gain. ${ }^{20,21}$ However, the selective 5- $\mathrm{HT}_{2 \mathrm{C}}$ agonist lorcaserin is an FDA-approved weight-loss treatment for patients who are obese (body mass index [BMI] $\geq 30 \mathrm{~kg} / \mathrm{m}^{2}$ ) or overweight (BMI $\geq 27 \mathrm{~kg} / \mathrm{m}^{2}$ in the presence of $\geq 1$ weight-related comorbid condition, such as hypertension or type 2 diabetes). ${ }^{22}$ The receptor binding profile of flibanserin suggests that it may have an impact on body weight as well.

Data collected in the clinical development program for flibanserin were utilized to retrospectively investigate the effect of flibanserin treatment on body weight in women with HSDD. Analyses included change in body weight associated with flibanserin in premenopausal women (pooled data from three randomized, placebo-controlled, 24-week trials ${ }^{9-11}$ ) and postmenopausal women (in a randomized, placebocontrolled, 24-week study ${ }^{13}$ ), and during long-term flibanserin use (in a 52-week, open-label, extension study ${ }^{23}$ ).

\section{Materials and Methods}

\section{Study design and participants}

This retrospective analysis included data from five studies from the flibanserin clinical development program in HSDD (Table 1). ${ }^{9-11,13,23}$ Study conduct was in compliance with the principles of the Declaration of Helsinki (1996) in accordance with the International Conference on Harmonisation Good Clinical Practice guidelines. All study protocols were approved by an institutional review board or independent ethics committee, and all participants provided written informed consent before the initiation of study procedures.

Three patient populations were included in this analysis:

(1) premenopausal women $\geq 18$ years old who were diagnosed with HSDD and enrolled in one of three randomized, double-blind, placebo-controlled trials that evaluated the safety and efficacy of flibanserin (study names: VIOLET, DAISY, BEGONIA) ${ }^{9-11}$;

(2) naturally postmenopausal women of any age who were diagnosed with HSDD and enrolled in a randomized, double-blind, placebo-controlled trial evaluating the safety and efficacy of flibanserin (SNOWDROP) ${ }^{13}$; and

(3) premenopausal women $\geq 18$ years old who were diagnosed with HSDD and had participated in a randomized placebo-controlled trial (VIOLET, DAISY, DAHLIA), ${ }^{9,10}$ a randomized withdrawal study (ROSE), ${ }^{12}$ or a pharmacokinetic study of flibanserin and were subsequently enrolled in a 52-week, open-label extension study (SUNFLOWER). ${ }^{23}$

Table 1. Studies Included in This Analysis

\begin{tabular}{|c|c|c|c|c|}
\hline Study name & Dates and locations & Study design & Participants & Study medication \\
\hline VIOLET $^{9}$ & July 2006 to April 2008 & $\begin{array}{l}\text { 24-Week R, DB, } \\
\text { PBO study }\end{array}$ & $\begin{array}{l}\text { Premenopausal } \\
\text { women } \geq 18 \text { years, }\end{array}$ & $\begin{array}{l}\text { Flibanserin } 50 \mathrm{mg} \\
\text { qhs }(n=295)^{\mathrm{a}}\end{array}$ \\
\hline NCT00360529 & $\begin{array}{l}54 \text { Sites in United States } \\
\text { and Canada }\end{array}$ & & $\begin{array}{l}\text { DSM-IV-TR diagnosis } \\
\text { of HSDD }\end{array}$ & $\begin{array}{l}\text { Flibanserin } 100 \mathrm{mg} \\
\text { qhs }(n=290) \\
\text { Placebo }(n=295)\end{array}$ \\
\hline DAISY $^{10}$ & July 2006 to March 2008 & $\begin{array}{l}\text { 24-Week R, DB, } \\
\text { PBO study }\end{array}$ & $\begin{array}{l}\text { Premenopausal } \\
\quad \text { women } \geq 18 \text { years, }\end{array}$ & $\begin{array}{l}\text { Flibanserin } 25 \mathrm{mg} \\
\quad \text { bid }(n=396)^{\mathrm{a}}\end{array}$ \\
\hline NCT00360555 & $\begin{array}{l}77 \text { Sites in United States } \\
\text { and Canada }\end{array}$ & & $\begin{array}{l}\text { DSM-IV-TR } \\
\text { diagnosis of HSDD }\end{array}$ & $\begin{array}{l}\text { Flibanserin } 50 \mathrm{mg} \\
\text { bid }(n=392)^{\mathrm{a}} \\
\text { Flibanserin } 100 \mathrm{mg} \\
\text { qhs }(n=395) \\
\text { Placebo }(n=398)\end{array}$ \\
\hline BEGONIA $^{11}$ & $\begin{array}{l}\text { October } 2009 \text { to } \\
\text { February } 2011\end{array}$ & $\begin{array}{l}\text { 24-Week R, DB, } \\
\text { PBO study }\end{array}$ & $\begin{array}{l}\text { Premenopausal } \\
\text { women } \geq 18 \text { years, }\end{array}$ & $\begin{array}{l}\text { Flibanserin } 100 \mathrm{mg} \\
\mathrm{qhs}(n=542)\end{array}$ \\
\hline NCT00996164 & 75 Sites in United States & & $\begin{array}{l}\text { DSM-IV-TR } \\
\text { diagnosis of HSDD }\end{array}$ & Placebo $(n=545)$ \\
\hline SNOWDROP $^{13}$ & $\begin{array}{l}\text { October } 2009 \text { to } \\
\text { March } 2011\end{array}$ & $\begin{array}{l}\text { 24-Week R, DB, } \\
\text { PBO study }\end{array}$ & $\begin{array}{l}\text { Naturally postmenopausal } \\
\text { women, DSM-IV-TR }\end{array}$ & $\begin{array}{l}\text { Flibanserin } 100 \mathrm{mg} \\
\text { qhs }(n=467)\end{array}$ \\
\hline NCT00996372 & 75 Sites in United States & & diagnosis of HSDD & Placebo $(n=480)$ \\
\hline SUNFLOWER $^{23}$ & $\begin{array}{l}\text { March } 2007 \\
\text { to August } 2009\end{array}$ & $\begin{array}{l}\text { 52-Week } \\
\text { OLE study }\end{array}$ & $\begin{array}{l}\text { Premenopausal } \\
\quad \text { women } \geq 18 \text { years, }\end{array}$ & $\begin{array}{l}\text { Flibanserin } 50 \\
\quad \text { or } 100 \mathrm{mg}\end{array}$ \\
\hline NCT00441558 & $\begin{array}{l}201 \text { Sites in United States } \\
\text { and Canada }\end{array}$ & & $\begin{array}{l}\text { DSM-IV-TR } \\
\text { diagnosis of HSDD }\end{array}$ & $\begin{array}{l}\text { qhs or } 25 \text { or } 50 \mathrm{mg} \\
\text { bid flexibly dosed } \\
(n=1723 \text { overall })\end{array}$ \\
\hline
\end{tabular}

${ }^{a}$ Analyses of the placebo-controlled studies excluded patients who received flibanserin at doses other than $100 \mathrm{mg}$ qhs.

bid, twice daily; DB, double-blind; DSM-IV-TR, Diagnostic and Statistical Manual of Mental Disorders, Fourth Edition, Text Revision; HSDD, hypoactive sexual desire disorder; OLE, open-label extension; PBO, placebo-controlled; qhs, each bedtime; R, randomized.

Data from Derogatis et al., ${ }^{9}$ Thorp et al., ${ }^{10}$ Katz et al., ${ }^{11}$ Simon et al., ${ }^{13}$ and Jayne et al. ${ }^{23}$ Additional information not found in these sources is from original study data. 
The inclusion criteria for all studies in this analysis required that participants were diagnosed with generalized acquired HSDD of $\geq 24$ weeks' duration (or $\geq 6$ months' duration for the SNOWDROP study) according to the Diagnostic and Statistical Manual of Mental Disorders, Fourth Edition, Text Revision (DSM-IV-TR) criteria.

Key exclusion criteria included other sexual dysfunctions; major depressive disorder within the previous 6 months; history of suicidal ideation or behavior; pelvic inflammatory disease, urinary tract or vaginal infection/vaginitis, cervicitis, interstitial cystitis, vulvodynia, or significant vaginal atrophy; current pregnancy or pregnancy within the last month (SUNFLOWER ${ }^{23}$ study) or last 6 months (VIOLET, ${ }^{9}$ DAISY, ${ }^{10}$ and BEGONIA studies); a history of cancer within the last 10 years; or blood abnormalities.

Use of certain medications was prohibited, including sex hormones (except for hormonal contraceptives in premenopausal women and systemic hormone therapy in postmenopausal women), dopamine agonists, benzodiazepines, prescription hypnotics, antidepressants, antipsychotics, mood stabilizers, antiepileptics, St. John's wort, metoclopramide, or chronically used narcotics. ${ }^{11,13,23}$ None of the studies in this analysis excluded patients on the basis of weight or BMI.

Patients received double-blind flibanserin or placebo in the 24-week randomized controlled trials and open-label flibanserin in the 52-week extension study. To obtain information about weight change associated with the recommended dose of flibanserin (100 $\mathrm{mg}$ each bedtime [qhs]), analyses of the placebocontrolled trials included only those patients treated with flibanserin $100 \mathrm{mg}$ qhs or placebo. The long-term, open-label study enrolled patients from a variety of flibanserin dosing regimens (and some patients previously on placebo). All patients received flibanserin $50 \mathrm{mg}$ qhs for 4 weeks, with flexible dosing thereafter to optimize efficacy and tolerability; permitted doses were 50 or $100 \mathrm{mg}$ qhs, or 25 or $50 \mathrm{mg}$ twice per day.

None of the studies in this analysis was designed to evaluate weight loss as a clinical benefit of flibanserin treatment; body weight was measured to assess weight loss and weight gain as potential adverse effects.

\section{Statistical analyses}

The analysis population for the 24-week placebocontrolled trials consisted of patients who were randomly assigned to treatment, received at least one dose of study medication, and had at least one assessment of body weight. For the three 24-week studies of premenopausal women, patient-level data were pooled by treatment group (flibanserin $100 \mathrm{mg}$ qhs vs. placebo) for assessments of body weight at baseline, and weeks 8,16 , and 24 .

In the premenopausal and postmenopausal patient populations, least-squares (LS) mean change in body weight from baseline to week 24 was compared for flibanserin versus placebo using analysis of covariance (ANCOVA) models with treatment group as a factor and baseline body weight as a covariate. In the premenopausal patient population, additional ANCOVA models were used to explore the effect of potential confounding variables (i.e., use of SSRIs or serotonin norepinephrine reuptake inhibitors [SNRIs], smoking status, baseline BMI level $\left[\leq 25\right.$ or $\left.>25 \mathrm{~kg} / \mathrm{m}^{2}\right]$, hormonal contraceptive use, and responder status on HSDD efficacy measures) on weight change.
In each model, except that for BMI level, the variable of interest and treatment group were used as factors with baseline body weight as a covariate; because BMI and weight are highly correlated, the model for BMI included baseline BMI (rather than baseline weight) as the covariate.

The analysis population for ANCOVAs of HSDD responder status consisted of patients in the overall analysis population who had at least one postbaseline efficacy assessment. To identify patients with a clinically meaningful benefit in HSDD symptoms, change from baseline to endpoint on measures of sexual functioning (i.e., number of satisfying sexual events [SSE], the Female Sexual Functioning Indexdesire domain [FSFI-D], and the Female Sexual Distress Scale-Revised-desire item [FSDS-R13]) was anchored to responses on the Patient Global Impression of Improvement (PGI-I) scale. For each measure of sexual functioning, a responder was defined as a patient with baseline to endpoint score change greater than the corresponding minimal response threshold (i.e., score of 3 [minimally improved]) on the PGI-I.

In the open-label extension study, change in body weight was assessed for patients who had $>12$ months (365 days) and $>18$ months (547 days) of exposure to flibanserin.

\section{Results}

\section{Patients}

Demographic and clinical characteristics of premenopausal and postmenopausal women treated with flibanserin $100 \mathrm{mg}$ qhs or placebo in a 24-week randomized controlled trial are shown in Table 2. In the pooled analysis of premenopausal women, 1210 patients in the flibanserin group and 1218 patients in the placebo group had at least 1 assessment of body weight and were included in this analysis. In the study of postmenopausal women, 467 flibanserintreated patients and 479 patients receiving placebo had at least 1 assessment of body weight and were included in this analysis. Within the premenopausal and postmenopausal patient populations, characteristics were similar in the flibanserin and placebo groups. In the long-term, open-label extension study, 880 patients received flibanserin for $>12$ months and 637 patients received flibanserin for $>18$ months.

\section{Change in weight after 24 weeks of treatment with flibanserin}

At week 24, LS mean change (standard error) in weight was $-1.4(0.1) \mathrm{kg}$ in the flibanserin group and $-0.1(0.1) \mathrm{kg}$ in the placebo group in premenopausal women $(p<0.0001)$ and -1.8 $(0.2) \mathrm{kg}$ in the flibanserin group and $-0.1(0.2) \mathrm{kg}$ in the placebo group in postmenopausal women $(p<0.0001)$ (Fig. 1). Weight loss differed significantly by BMI in the premenopausal patient population; greater LS mean weight loss was observed in women with higher $\left(>25 \mathrm{~kg} / \mathrm{m}^{2}\right)$ versus lower baseline BMI $(p<0.01)$ (Table 3$)$.

None of the other baseline factors investigated (i.e., SSRI/ SNRI use, smoking status, and hormonal contraceptive use) had a significant effect on weight change, after accounting for the effects of baseline body weight and treatment group. Similarly, there was no significant difference between treatment responders and nonresponders (as determined by change on HSDD efficacy measures [number of SSE, 
Table 2. Demographic and Baseline Clinical Characteristics and Selected Concomitant Medications in 24-Week Randomized Controlled Studies (All Treated Population)

\begin{tabular}{|c|c|c|c|c|}
\hline \multirow[b]{2}{*}{ Characteristics } & \multicolumn{2}{|c|}{ 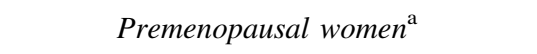 } & \multicolumn{2}{|c|}{ Postmenopausal women } \\
\hline & $\begin{array}{c}\text { Flibanserin } \\
100 \mathrm{mg} \text { qhs }(\mathrm{n}=1227)\end{array}$ & $\begin{array}{c}\text { Placebo } \\
(\mathrm{n}=1238)\end{array}$ & $\begin{array}{c}\text { Flibanserin } \\
100 \mathrm{mg} q \mathrm{hs}(\mathrm{n}=467)\end{array}$ & $\begin{array}{l}\text { Placebo } \\
(\mathrm{n}=480)\end{array}$ \\
\hline Age, years, mean (SD) & $35.9(7.5)$ & $36.2(7.3)$ & $55.4(5.4)$ & $55.5(5.3)$ \\
\hline \multicolumn{5}{|l|}{ Race, $n(\%)$} \\
\hline White & $1073(87.4)$ & $1089(88.0)$ & $425(91.0)$ & $444(92.5)$ \\
\hline Black/African American & $131(10.7)$ & $119(9.6)$ & $35(7.5)$ & $27(5.6)$ \\
\hline Asian & $20(1.6)$ & $21(1.7)$ & $4(0.9)$ & $4(0.8)$ \\
\hline Other & $3(0.2)$ & $9(0.7)$ & $3(0.6)$ & $5(1.0)$ \\
\hline Hispanic ethnicity, $n(\%)$ & $117(9.5)$ & $111(9.0)$ & $28(6.0)$ & $23(4.8)$ \\
\hline Duration of HSDD, months, mean (SD) & $53.9(42.6)$ & $57.0(47.1)$ & $59.5(46.0)$ & $61.6(51.3)^{\mathrm{b}}$ \\
\hline Weight, $\mathrm{kg}$, mean (SD) & $73.6(18.0)$ & 72.9 (17.3) & $74.3(15.4)$ & $73.2(15.1)^{\mathrm{b}}$ \\
\hline BMI, $\mathrm{kg} / \mathrm{m}^{2}$, mean (SD) & $27.0(6.2)$ & $26.8(6.5)$ & $27.7(5.7)$ & $27.3(5.4)^{c}$ \\
\hline \multicolumn{5}{|l|}{ BMI category $\left(\mathrm{kg} / \mathrm{m}^{2}\right), n(\%)$} \\
\hline Underweight $(<18.5)$ & $21(1.7)$ & $23(1.9)$ & $2(0.4)$ & $7(1.5)$ \\
\hline Normal $(18.5$ to $<25)$ & $559(45.6)$ & $569(46.0)$ & $164(35.3)$ & $175(36.7)$ \\
\hline Overweight $(25$ to $<30)$ & $330(26.9)$ & $341(27.5)$ & $165(35.6)$ & $161(33.8)$ \\
\hline Obese $(\geq 30)$ & $313(25.5)$ & $301(24.3)$ & $133(28.7)$ & $134(28.1)$ \\
\hline Current smoker, $n(\%)$ & $159(13.0)$ & $157(12.7)$ & $53(11.3)$ & $55(11.5)$ \\
\hline \multicolumn{5}{|l|}{ Selected concomitant medications } \\
\hline Hormonal contraceptive use, $n(\%)$ & $489(41.1)$ & $487(41.0)$ & - & - \\
\hline Systemic hormone therapy, $n(\%)$ & - & - & $74(15.9)$ & $74(15.4)$ \\
\hline SSRI/SNRI use, $n(\%)^{\mathrm{d}}$ & $47(2.0)$ & $21(1.7)$ & $12(2.8)$ & $12(2.7)$ \\
\hline
\end{tabular}

${ }^{a}$ Three studies (VIOLET, DAISY, and BEGONIA) pooled.

$\mathrm{b}_{n=479 .}$

${ }^{\mathrm{c}} n=477$.

${ }^{\mathrm{d}}$ Protocol violation.

BMI, body mass index; SD, standard deviation; SNRI, serotonin-norepinephrine reuptake inhibitors; SSRI, selective serotonin reuptake inhibitor.

FIG. 1. Mean change from baseline weight $(\mathrm{kg})$ after 8,16 , and 24 weeks of treatment with flibanserin $100 \mathrm{mg}$ qhs or placebo in (A) premenopausal women and (B) postmenopausal women. Mean (SD) baseline weight was 73.7 (17.9) $\mathrm{kg}$ in the flibanserin group and 73.1 (17.4) $\mathrm{kg}$ in the placebo group for premenopausal women, and $74.4(15.4) \mathrm{kg}$ in the flibanserin group and $73.4(15.2) \mathrm{kg}$ in the placebo group for postmenopausal women. Error bars represent \pm 1 standard error.

$* p<0.0001 ;{ }^{\dagger} p<0.005$. qhs, each bedtime; SD, standard deviation.
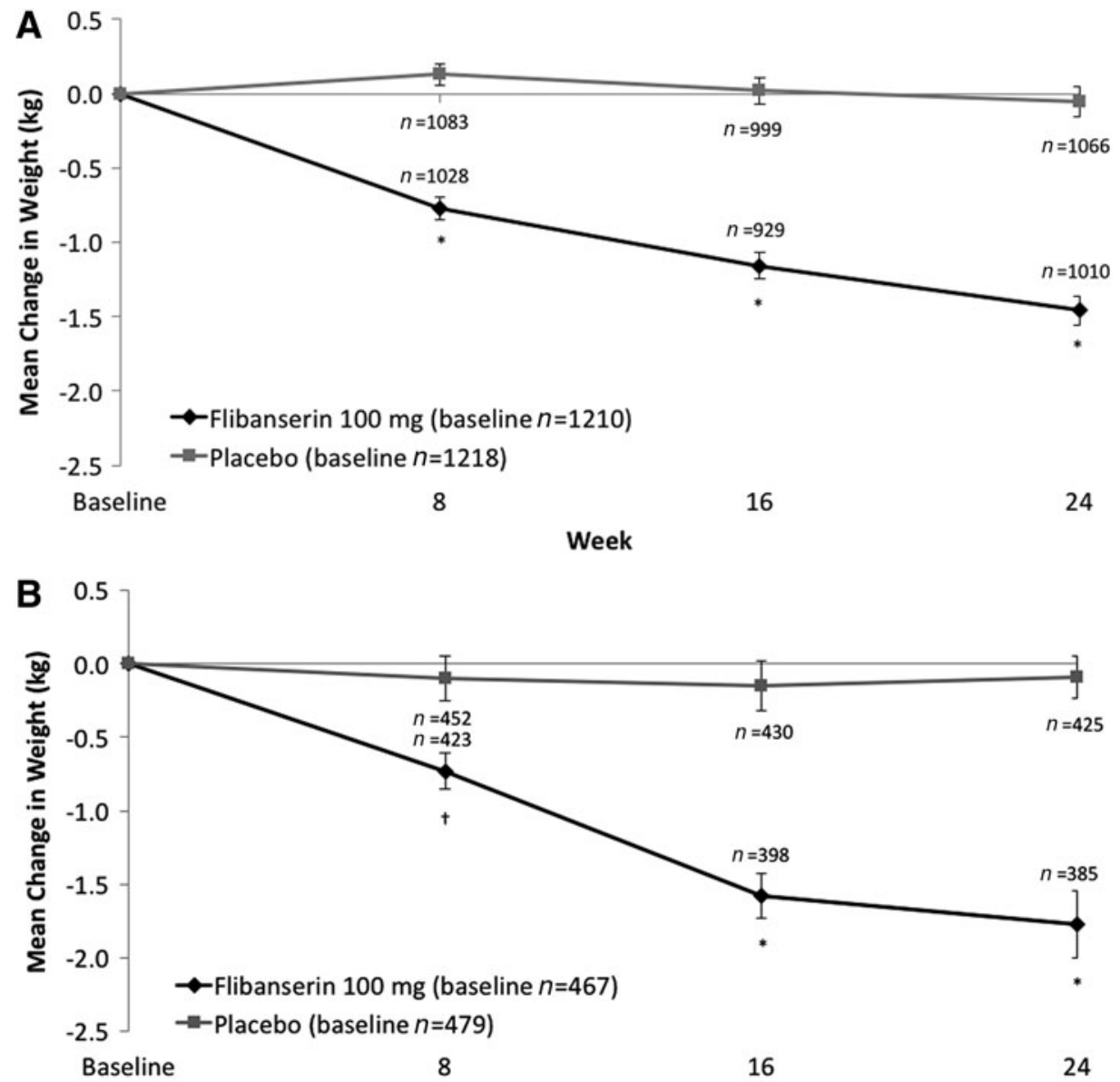

Week 
Table 3. Subgroup Analysis of Change

in Body Weight for Selected Baseline

Characteristics and Treatment Response

\begin{tabular}{|c|c|c|c|}
\hline Variable & $\mathrm{N}$ & $\begin{array}{l}\text { LS mean } \\
(S E) \text { change } \\
\text { in body } \\
\text { weight }(k g)\end{array}$ & $\mathrm{p}^{\mathrm{a}}$ \\
\hline \multicolumn{4}{|c|}{ SSRI/SNRI use ${ }^{b}$} \\
\hline Yes & 49 & $-1.6(0.5)$ & \multirow[t]{2}{*}{0.0861} \\
\hline No & 2331 & $-0.7(0.1)$ & \\
\hline \multicolumn{4}{|c|}{ Current smoker } \\
\hline Yes & 159 & $-0.7(0.3)$ & \multirow[t]{2}{*}{0.9405} \\
\hline No & 1148 & $-0.7(0.1)$ & \\
\hline \multicolumn{4}{|l|}{ Baseline BMI } \\
\hline$\leq 25 \mathrm{~kg} / \mathrm{m}^{2}$ & 1157 & $-0.5(0.1)$ & \multirow[t]{2}{*}{0.0015} \\
\hline$>25 \mathrm{~kg} / \mathrm{m}^{2}$ & 1263 & $-1.0(0.1)$ & \\
\hline \multicolumn{4}{|c|}{ Hormonal contraceptive use } \\
\hline Yes & 523 & $-0.8(0.1)$ & \multirow[t]{2}{*}{0.4883} \\
\hline No & 784 & $-0.6(0.1)$ & \\
\hline \multicolumn{4}{|c|}{ Treatment response } \\
\hline SSE & & & \multirow{3}{*}{0.3303} \\
\hline Yes & 471 & $-0.8(0.1)$ & \\
\hline No & 812 & $-0.6(0.1)$ & \\
\hline \multicolumn{4}{|l|}{ FSFI-D } \\
\hline Yes & 495 & $-0.7(0.1)$ & \multirow[t]{2}{*}{0.8016} \\
\hline No & 810 & $-0.7(0.1)$ & \\
\hline \multicolumn{4}{|l|}{ FSDS-R13 } \\
\hline Yes & 610 & $-0.7(0.1)$ & \multirow[t]{2}{*}{0.9961} \\
\hline No & 696 & $-0.7(0.1)$ & \\
\hline
\end{tabular}

${ }^{a} p$ Value for the contrast between the two levels of each variable, after accounting for the effects of baseline body weight (or baseline BMI in the model for BMI level) and treatment group.

${ }^{\mathrm{b}}$ Protocol violation.

FSDS-R13, Female Sexual Distress Scale-Revised-desire item; FSFI-D, Female Sexual Function Index-desire domain; LS, least squares; SE, standard error; SSE, satisfying sexual events.

FSFI-D score, FSDS-R13 score]) in change from baseline body weight.

In each analysis, there was a statistically significant association of weight change at week 24 with baseline body weight and treatment group such that higher baseline body weight and treatment with flibanserin (vs. placebo) were associated with greater weight loss.

At the end of 24 weeks, $21.0 \%$ of premenopausal women receiving flibanserin had lost $\geq 5 \%$ of their baseline body weight compared with $7.8 \%$ of premenopausal women receiving placebo $(p<0.0001) ; 3.8 \%$ and $2.0 \%$ of patients, respectively, experienced $\geq 10 \%$ weight loss (Fig. 2). Similarly, $24.7 \%$ of postmenopausal women receiving flibanserin had lost $\geq 5 \%$ of their baseline body weight at week 24 , compared with $7.3 \%$ of postmenopausal women receiving placebo ( $p<0.0001) ; 5.2 \%$ and $1.7 \%$ of patients, respectively, experienced $\geq 10 \%$ weight loss. At week 24 , weight gain $\geq 7 \%$ (the FDA definition of significant weight gain ${ }^{24}$ ) was observed in $1.8 \%$ and $3.4 \%$ of premenopausal women in the flibanserin and placebo groups, respectively, and in $2.1 \%$ and $2.8 \%$ of postmenopausal women, respectively.

To evaluate a possible dose-response effect, an analysis of once-daily flibanserin at a dose lower than currently recommended included 295 premenopausal women with
HSDD who received flibanserin $50 \mathrm{mg}$ qhs (in the VIOLET study). ${ }^{9}$ For flibanserin $50 \mathrm{mg}$ qhs, LS mean weight change at week 24 was $-0.6 \mathrm{~kg}$ (compared with $-0.1 \mathrm{~kg}$ for placebo and $-1.4 \mathrm{~kg}$ for flibanserin $100 \mathrm{mg}$ ); weight loss of $\geq 5 \%$ and $\geq 10 \%$ was experienced by $8.9 \%$ and $1.9 \%$ of women, respectively (compared with $7.8 \%$ and $2.0 \%$, respectively, for placebo and $21.0 \%$ and $3.8 \%$, respectively, for flibanserin $100 \mathrm{mg}$ ).

Nausea, a common adverse event with flibanserin, was assessed as a possible contributor to weight loss. However, the incidence of nausea in premenopausal women with HSDD who received flibanserin $100 \mathrm{mg}$ in the 24-week randomized, placebo-controlled trials was somewhat higher $(7.1 \%)$ in women with weight loss $<5 \%$ compared with $5.8 \%$ in women with weight loss $\geq 5 \%$. The incidence of nausea was similar in postmenopausal women with weight loss $<5 \%$ versus weight loss $\geq 5 \%$ (incidence of nausea $5.3 \%$ and $5.6 \%$, respectively).

\section{Change in weight after longer term treatment with flibanserin}

In addition, weight loss was observed after 12 and 18 months of treatment with flibanserin (Table 4). In premenopausal patients, mean (standard deviation) weight change from parent study baseline equaled $-1.0(6.1) \mathrm{kg}$ in patients with flibanserin exposure $>12$ months and $-1.2(5.4) \mathrm{kg}$ in patients with flibanserin exposure $>18$ months. Weight loss $>5 \%$ from parent study baseline was observed in $25.4 \%$ of patients with $>12$ months of treatment with flibanserin and $26.9 \%$ of patients with $>18$ months of treatment; weight loss $\geq 10 \%$ was experienced by $7.8 \%$ and $8.4 \%$ of patients, respectively.

\section{Discussion}

In this retrospective analysis of clinical studies, flibanserin was associated with statistically significant weight loss compared with placebo in both premenopausal and postmenopausal women with HSDD who received 6 months of double-blind treatment. In addition, flibanserin-associated weight loss was comparable in both premenopausal and postmenopausal women. Also, there was no evidence of weight regain based on the assessment of patients treated with flibanserin for 18 months. Hormonal contraceptive use, SSRI/SNRI use, BMI level, and smoking status (assessed at baseline); nausea (assessed as an adverse event); and treatment responder status (based on clinically meaningful change in HSDD efficacy measures) did not demonstrate a significant effect on weight change.

The patients with HSDD who participated in these clinical trials of flibanserin were not selected for overweight or obesity, nor did they enter the studies with the goal of losing weight. In the patients with HSDD included in this analysis, baseline BMI ranged from underweight to obese, with rates of overweight (premenopausal women, 27.2\%; postmenopausal women, $34.4 \%$ ) and obesity (premenopausal women, $24.9 \%$; postmenopausal women, $28.2 \%$ ) somewhat lower than currently observed in the general population of adult women in the United States, ${ }^{25}$ which may represent a healthy user type bias in these clinical trials. Nonetheless, comparing these findings with studies of FDA-approved weight-loss drugs may provide some context regarding the magnitude of weight loss observed.

In double-blind, placebo-controlled studies of FDA-approved weight-loss drugs (i.e., lorcaserin, naltrexone/bupropion, 
FIG. 2. Proportion of patients who lost $5 \%$ or more, $7 \%$ or more, and $10 \%$ or more of their baseline body weight after 24 weeks of treatment with flibanserin $100 \mathrm{mg}$ qhs or placebo in (A) premenopausal women and (B) postmenopausal women. ${ }^{*} p<0.0001 ;{ }^{\dagger} p<0.05 ;{ }^{\ddagger} p<0.01$.
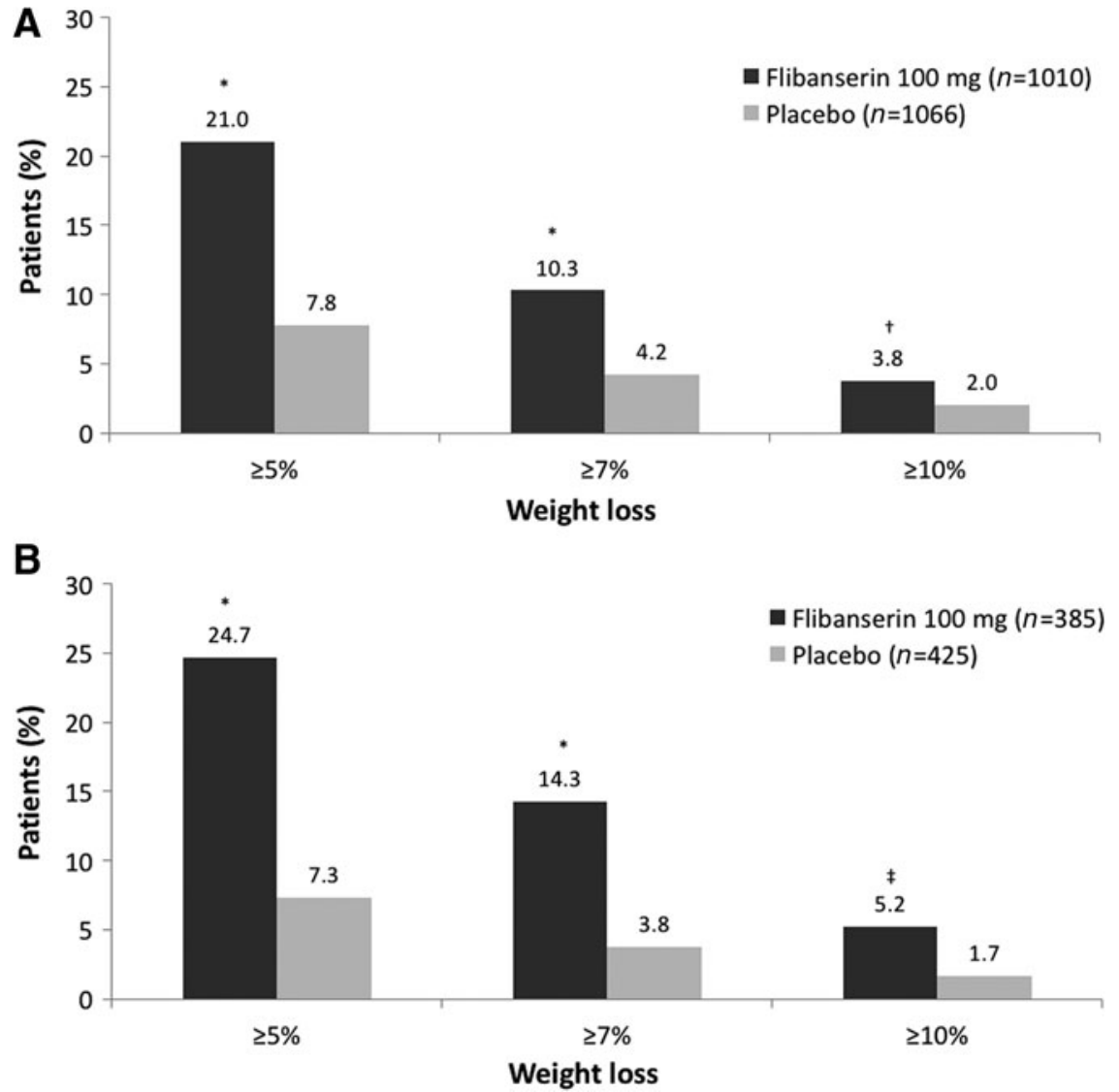

Table 4. Change from Baseline Body Weight After at Least 12 and 18 Months of Treatment WITH FLIBANSERIN

\begin{tabular}{|c|c|c|}
\hline Parameter & $\begin{array}{c}\text { Exposure }>12 \\
\text { months } \\
(\mathrm{n}=880)\end{array}$ & $\begin{array}{c}\text { Exposure }>18 \\
\quad \text { months } \\
(\mathrm{n}=637)\end{array}$ \\
\hline $\begin{array}{l}\text { Baseline mean (SD) weight } \\
\text { in parent study, } \mathrm{kg}\end{array}$ & $73.2(18.0)$ & $73.6(18.4)$ \\
\hline $\begin{array}{l}\text { Baseline mean (SD) weight } \\
\text { in open-label study, kg }\end{array}$ & $73.0(18.2)$ & $73.3(18.7)$ \\
\hline $\begin{array}{l}\text { Mean (SD) change from } \\
\text { parent study baseline } \\
\text { to final study visit, } \mathrm{kg}\end{array}$ & $-1.0(6.1)$ & $-1.2(5.4)$ \\
\hline $\begin{array}{l}\text { Mean (SD) change from } \\
\text { open-label study baseline } \\
\text { to final study visit, kg }\end{array}$ & $-0.8(5.3)$ & $-0.9(4.4)$ \\
\hline \multicolumn{3}{|c|}{$\begin{array}{l}\text { Percent change from parent study baseline } \\
\text { to final study visit, } n(\%)\end{array}$} \\
\hline Weight loss $\geq 5 \%$ & $198(25.4)$ & $166(26.9)$ \\
\hline Weight loss $\geq 7 \%$ & 133 & $8.0)$ \\
\hline Weight loss $\geq 10 \%$ & $61(7.8)$ & $52(8.4)$ \\
\hline Weight gain $\geq 7 \%$ & $68(8.7)$ & $54(8.7)$ \\
\hline \multicolumn{3}{|c|}{$\begin{array}{l}\text { Percent change from open-label study baseline } \\
\text { to final study visit, } n(\%)\end{array}$} \\
\hline Weight loss $\geq 5 \%$ & $153(19.5)$ & $129(20.7)$ \\
\hline Weight loss $\geq 7 \%$ & $91(11.6)$ & $80(12.9)$ \\
\hline Weight loss $\geq 10 \%$ & $39(5.0)$ & $34(5.5)$ \\
\hline Weight gain $\geq 7 \%$ & $43(5.5)$ & $39(6.3)$ \\
\hline
\end{tabular}

Results at baseline and final study visit include all patients with nonmissing data. phentermine/topiramate, and liraglutide), patients received dietary and exercise counseling, in addition to medication. Mean weight loss in overweight/obese patients (70\%-85\% of whom were women) ranged from 5 to $10 \mathrm{~kg}$ for the active study medication and 1 to $3 \mathrm{~kg}$ for placebo after 52 to 56 weeks of treatment. ${ }^{22,26-31}$ Studies that reported mean weight change at interim time points showed similar weight loss at 24-28 weeks and at 52-56 weeks. ${ }^{26,28,31}$

Between $40 \%$ and $70 \%$ of patients treated with FDAapproved weight-loss medications (and 16\%-27\% of patients receiving placebo) lost $\geq 5 \%$ of their baseline body weight at the typical month-12 study endpoint..$^{22,26-31}$ In these studies of women with HSDD, mean baseline BMI (premenopausal women, $26.9 \mathrm{~kg} / \mathrm{m}^{2}$; postmenopausal women, $27.5 \mathrm{~kg} / \mathrm{m}^{2}$ ) was substantially lower than that in studies of weight-loss medications $\left(35.8-38.3 \mathrm{~kg} / \mathrm{m}^{2}\right)$; in addition, HSDD patients were generally not attempting to lose weight and did not receive the ancillary therapies provided in weight-loss studies (e.g., nutritional counseling, exercise counseling). ${ }^{26-31}$

The lower BMI in these studies, as well as the lack of patient intent to lose weight, makes the weight loss in the flibanserin-treated patients all the more intriguing. Mean weight loss was $1.5-1.8 \mathrm{~kg}$ after 6 months of treatment with flibanserin and $1.0 \mathrm{~kg}$ after 12 months of treatment, with mean weight remaining essentially unchanged in patients who received placebo. Weight loss $\geq 5 \%$ from baseline was observed at month 6 in $21 \%-25 \%$ of patients receiving flibanserin and only $7 \%-8 \%$ of patients receiving placebo, and at month 12 in $25 \%$ of flibanserin-treated patients. It is possible that weight loss observed in the flibanserin studies was 
limited by a floor effect, since baseline weight was lower in these studies compared with clinical trials of weight-loss medications.

The mechanism(s) of action by which flibanserin produces weight loss are currently unknown. The receptor binding affinity of flibanserin is highest for $5-\mathrm{HT}_{1 \mathrm{~A}}$ receptors (as an agonist) and $5-\mathrm{HT}_{2 \mathrm{~A}}$ receptors (as an antagonist). ${ }^{6}$ Both $5-\mathrm{HT}_{1 \mathrm{~A}}$ agonist activity and $5-\mathrm{HT}_{2 \mathrm{~A}}$ antagonist activity result in the inhibition of glutamate neurons, thereby reducing serotonin release in the prefrontal cortex. ${ }^{6}$

The complex role of serotonin in mammalian energy balance has not been completely elucidated at this time. ${ }^{32}$ Based on evidence from numerous studies of the serotonin system, it is generally understood that enhanced serotonergic neurotransmission is associated with suppression of food intake and reduction in body weight. ${ }^{19,26,32}$ However, mirtazapine, an atypical antidepressant with agonist effects at the 5- $\mathrm{HT}_{1 \mathrm{~A}}$ receptor and antagonist effects at the $5-\mathrm{HT}_{2 \mathrm{~A}}$ receptor (similar to flibanserin), is generally known to cause weight gain. ${ }^{33,34}$ Furthermore, flibanserin is a minor $5-\mathrm{HT}_{2 \mathrm{C}}$ receptor antagonist, ${ }^{1}$ yet the $5-\mathrm{HT}_{2 \mathrm{C}}$ receptor agonist lorcaserin has been approved as a weight-loss drug. ${ }^{22}$ Thus, the serotoninrelated activity of flibanserin does not appear to explain the observed weight loss in this analysis of patients treated with flibanserin. ${ }^{32}$

Either flibanserin affects body weight via a serotoninbased process that is as yet unknown or weight loss associated with flibanserin can be accounted for by non-serotoninrelated mechanisms (e.g., enhanced cortical norepinephrine release). It is interesting to note that no significant association was observed in this analysis for weight loss and treatment response (defined as clinically meaningful change on HSDD efficacy measures), suggesting that the flibanserin mechanism of action for weight loss may differ from that for improved sexual function.

This analysis has several limitations. The studies included in this analysis were designed to evaluate the efficacy and safety of flibanserin for the treatment of women with HSDD. This analysis of change in body weight is, therefore, post hoc and exploratory in nature. There was no systematic attempt to collect information about the use of medications or supplements known to affect body weight or participation in programs intended to promote weight loss, nor was dietary or exercise counseling provided. Because this analysis included only observed cases, weight change was not assessed in patients who discontinued early from the underlying studies. Further investigation is needed to more rigorously evaluate changes in body weight associated with flibanserin treatment.

\section{Conclusions}

This retrospective analysis showed that treatment with flibanserin $100 \mathrm{mg}$ qhs in women with HSDD was associated with statistically significant weight loss compared with placebo in both premenopausal and postmenopausal patients. Weight loss without apparent weight regain was also observed during longer term, open-label flibanserin treatment of up to 18 months. In contrast to more typical serotonergic antidepressants, weight gain does not appear to be a clinical concern with flibanserin. Women treated with flibanserin for HSDD may experience weight loss.

\section{Acknowledgments}

Technical editorial and medical writing assistance was provided under the direction of the authors by Nancy Holland, PhD, Synchrony Medical Communications, LLC (West Chester, PA). Funding for this support was provided by Valeant Pharmaceuticals North America, LLC (Bridgewater, NJ).

\section{Author Disclosure Statement}

Dr. Kornstein reports receiving research support from Allergan, Palatin Technologies, Pfizer, and Takeda Pharmaceutical Co., Ltd.; and serving as a consultant to or on the advisory board for Allergan, Forest, Eli Lilly and Company, Pfizer, Takeda Pharmaceutical Co., Ltd., Palatin Technologies, Shire, and Sunovion Pharmaceuticals, Inc. Dr. Simon reports receiving grant/research support from AbbVie, Inc., Allergan, plc, Agile Therapeutics, Bayer Healthcare, LLC, New England Research Institute, Inc., ObsEva SA, Palatin Technologies, Symbio Research, Inc., and TherapeuticsMD; serving as a consultant to or on the advisory board for AbbVie, Inc., Allergan, plc, AMAG Pharmaceuticals, Inc., Amgen, Inc., Ascend Therapeutics, Azure Biotech, Inc., Bayer Healthcare Pharmaceuticals Inc., CEEK Enterprises, LLC, Covance Inc., Millendo Therapeutics, Inc., Mitsubishi Tanabe Pharma Development America, Inc., ObsEva SA, Radius Health, Inc., Sanofi S.A., Sebela Pharmaceuticals, Inc., Sermonix Pharmaceuticals, Inc., Shionogi, Inc., Symbiotec Pharmalab, TherapeuticsMD, and Valeant Pharmaceuticals North America, LLC; serving on the speakers' bureau for Duchesnay USA, Novo Nordisk, Shionogi, Inc., and Valeant Pharmaceuticals (Laval, Canada); and being a stock shareholder of Sermonix Pharmaceuticals. Dr. Apfel reports serving as a consultant to Valeant Pharmaceuticals (Laval, Canada). Drs. Yuan, Barbour, and Kissling are employees of Valeant Pharmaceuticals North America, LLC (Bridgewater, $\mathrm{NJ}$ ).

\section{Funding}

This study was supported by Boehringer Ingelheim. Boehringer Ingelheim was involved in study design, data collection, and data analysis. Boehringer Ingelheim had no involvement in interpretation of data, writing of the report, or the decision to submit the report for publication. Funding for technical editorial and medical writing assistance was provided by Valeant Pharmaceuticals. Valeant Pharmaceuticals was involved in interpretation of data and writing of the report.

\section{References}

1. Addyi $^{\circledR}$ (flibanserin) tablets, for oral use [package insert]. Bridgewater, NJ: Sprout Pharmaceuticals, a division of Valeant North America, LLC, 2016.

2. Joffe H, Chang C, Sewell C, et al. FDA approval of flibanserin-Treating hypoactive sexual desire disorder. $\mathrm{N}$ Engl J Med 2016;374:101-104.

3. Borsini F, Evans K, Jason K, Rohde F, Alexander B, Pollentier S. Pharmacology of flibanserin. CNS Drug Rev 2002;8:117-142.

4. Marazziti D, Palego L, Giromella A, et al. Regiondependent effects of flibanserin and buspirone on adenylyl cyclase activity in the human brain. Int $\mathrm{J}$ Neuropsychopharmacol 2002;5:131-140. 
5. Allers KA, Dremencov E, Ceci A, et al. Acute and repeated flibanserin administration in female rats modulates monoamines differentially across brain areas: A microdialysis study. J Sex Med 2010;7:1757-1767.

6. Stahl SM, Sommer B, Allers KA. Multifunctional pharmacology of flibanserin: Possible mechanism of therapeutic action in hypoactive sexual desire disorder. J Sex Med 2011;8:15-27.

7. Pfaus JG. Pathways of sexual desire. J Sex Med 2009;6: 1506-1533.

8. Stahl SM. Circuits of sexual desire in hypoactive sexual desire disorder. J Clin Psychiatry 2010;71:518-519.

9. Derogatis LR, Komer L, Katz M, et al. Treatment of hypoactive sexual desire disorder in premenopausal women: Efficacy of flibanserin in the VIOLET Study. J Sex Med 2012;9:1074-1085.

10. Thorp J, Simon J, Dattani D, et al. Treatment of hypoactive sexual desire disorder in premenopausal women: Efficacy of flibanserin in the DAISY study. J Sex Med 2012;9:793804.

11. Katz M, Derogatis LR, Ackerman R, et al. Efficacy of flibanserin in women with hypoactive sexual desire disorder: Results from the BEGONIA trial. J Sex Med 2013;10: 1807-1815.

12. Goldfischer ER, Breaux J, Katz M, et al. Continued efficacy and safety of flibanserin in premenopausal women with hypoactive sexual desire disorder (HSDD): Results from a randomized withdrawal trial. J Sex Med 2011;8:3160-3172.

13. Simon JA, Kingsberg SA, Shumel B, Hanes V, Garcia M Jr, Sand M. Efficacy and safety of flibanserin in postmenopausal women with hypoactive sexual desire disorder: Results of the SNOWDROP trial. Menopause 2014;21:633-640.

14. Bello NT, Liang NC. The use of serotonergic drugs to treat obesity-Is there any hope? Drug Des Devel Ther 2011;5: 95-109.

15. Ratner C, Ettrup A, Bueter M, et al. Cerebral markers of the serotonergic system in rat models of obesity and after Roux-en-Y gastric bypass. Obesity (Silver Spring) 2012;20: 2133-2141.

16. Berglund ED, Liu C, Sohn JW, et al. Serotonin 2C receptors in pro-opiomelanocortin neurons regulate energy and glucose homeostasis. J Clin Invest 2013;123:5061-5070.

17. Dill MJ, Shaw J, Cramer J, Sindelar DK. 5-HT1A receptor antagonists reduce food intake and body weight by reducing total meals with no conditioned taste aversion. Pharmacol Biochem Behav 2013;112:1-8.

18. Yang HY, Tae J, Seo YW, et al. Novel pyrimidoazepine analogs as serotonin 5- $\mathrm{HT}_{2 \mathrm{~A}}$ and $5-\mathrm{HT}_{2 \mathrm{C}}$ receptor ligands for the treatment of obesity. Eur J Med Chem 2013;63:558-569.

19. Haahr ME, Hansen DL, Fisher PM, et al. Central 5-HT neurotransmission modulates weight loss following gastric bypass surgery in obese individuals. J Neurosci 2015;35: 5884-5889.

20. Blumenthal SR, Castro VM, Clements CC, et al. An electronic health records study of long-term weight gain following antidepressant use. JAMA Psychiatry 2014;71:889-896.
21. Harvey BH, Bouwer CD. Neuropharmacology of paradoxic weight gain with selective serotonin reuptake inhibitors. Clin Neuropharmacol 2000;23:90-97.

22. Belviq (lorcaserin hydrochloride) tablets, for oral use, CIV [package insert]. Zofingen: Arena Pharmaceuticals $\mathrm{GmbH}$, 2014.

23. Jayne C, Simon JA, Taylor LV, Kimura T, Lesko LM. Openlabel extension study of flibanserin in women with hypoactive sexual desire disorder. J Sex Med 2012;9:3180-3188.

24. Sachs GS, Guille C. Weight gain associated with use of psychotropic medications. J Clin Psychiatry 1999;60 Suppl 21:16-19.

25. Ogden CL, Carroll MD, Kit BK, Flegal KM. Prevalence of childhood and adult obesity in the United States, 20112012. JAMA 2014;311:806-814.

26. Smith SR, Weissman NJ, Anderson CM, et al. Multicenter, placebo-controlled trial of lorcaserin for weight management. N Engl J Med 2010;363:245-256.

27. Fidler MC, Sanchez M, Raether B, et al. A one-year randomized trial of lorcaserin for weight loss in obese and overweight adults: The BLOSSOM trial. J Clin Endocrinol Metab 2011;96:3067-3077.

28. Apovian CM, Aronne L, Rubino D, et al. A randomized, phase 3 trial of naltrexone SR/bupropion SR on weight and obesity-related risk factors (COR-II). Obesity (Silver Spring) 2013;21:935-943.

29. Greenway FL, Fujioka K, Plodkowski RA, et al. Effect of naltrexone plus bupropion on weight loss in overweight and obese adults (COR-I): A multicentre, randomised, doubleblind, placebo-controlled, phase 3 trial. Lancet 2010;376: 595-605.

30. Gadde KM, Allison DB, Ryan DH, et al. Effects of low-dose, controlled-release, phentermine plus topiramate combination on weight and associated comorbidities in overweight and obese adults (CONQUER): A randomised, placebocontrolled, phase 3 trial. Lancet 2011;377:1341-1352.

31. Pi-Sunyer X, Astrup A, Fujioka K, et al. A randomized, controlled trial of $3.0 \mathrm{mg}$ of liraglutide in weight management. N Engl J Med 2015;373:11-22.

32. Donovan MH, Tecott LH. Serotonin and the regulation of mammalian energy balance. Front Neurosci 2013;7:36.

33. Serretti A, Mandelli L. Antidepressants and body weight: A comprehensive review and meta-analysis. J Clin Psychiatry 2010;71:1259-1272.

34. REMERON ${ }^{\circledR}$ (mirtazapine) tablets [package insert]. Roseland, NJ: Organon USA, Inc., 2007.

Address correspondence to:

Susan G. Kornstein, MD

Department of Psychiatry

and Institute for Women's Health

Virginia Commonwealth University

PO Box 980319

Richmond, VA 23298

E-mail: susan.kornstein@vcuhealth.org 